Article

\title{
Green Labelled Rice Shows a Higher Nutritional and Physiochemical Quality Than Conventional Rice in China
}

\author{
Jiuliang $X u^{1,2,3}{ }^{D}$, Jiahui Zhong ${ }^{1}$, Baozhen Zhang $^{1}$ and Xuexian $\mathrm{Li}^{1,2,3, *(D)}$ \\ 1 The Key Plant-Soil Interaction Laboratory, Department of Plant Nutrition, Ministry of Education, \\ China Agricultural University, Beijing 100193, China; jlxu9@cau.edu.cn (J.X.); zhongjiahuicau@126.com (J.Z.); \\ zhangBzzzZ@163.com (B.Z.) \\ 2 National Academy of Agriculture Green Development, China Agricultural University, Beijing 100193, China \\ 3 Chinese Academy of Green Food Development, Beijing 100193, China \\ * Correspondence: steve@cau.edu.cn; Tel.: +86-010-6273-3640
}

Citation: Xu, J.; Zhong, J.; Zhang, B.; Li, X. Green Labelled Rice Shows a Higher Nutritional and

Physiochemical Quality Than Conventional Rice in China. Foods 2021, 10, 915. https://doi.org/ 10.3390/foods 10050915

Academic Editors: Ken'ichi Ohtsubo, Carla Brites and Cristina M. Rosell

Received: 1 April 2021

Accepted: 19 April 2021

Published: 21 April 2021

Publisher's Note: MDPI stays neutral with regard to jurisdictional claims in published maps and institutional affiliations.

Copyright: (c) 2021 by the authors. Licensee MDPI, Basel, Switzerland. This article is an open access article distributed under the terms and conditions of the Creative Commons Attribution (CC BY) license (https:/ / creativecommons.org/licenses/by/ $4.0 /)$.

\begin{abstract}
In China, green food refers to a wide array of certified agricultural and processed edible commodities that are produced strictly following defined standard protocols and labelled with a specified "Green Food" logo. The demand for green labelled rice is rapidly growing due to its higher quality and adherence to safety standards compared to conventional rice. Therefore, the physicochemical and nutritional quality of green rice needs to be further investigated for consumers' benefits. Using Daohuaxiang 2, one of the most famous types of green rice, we found that green rice was significantly superior to conventional rice in terms of thousand kernel weight, chalkiness, amylose content, and rheological properties. Green rice contained lower levels of heavy metals than conventional rice due to a dramatic reduction in chemical inputs during its cultivation. The concentrations of $\mathrm{Cr}, \mathrm{As}, \mathrm{Cd}, \mathrm{Pb}$ in green rice decreased, respectively, from 98.7 to $180.1 \mu \mathrm{g} / \mathrm{kg}, 49.8$ to $62.3 \mu \mathrm{g} / \mathrm{kg}, 7.8$ to $9.1 \mu \mathrm{g} / \mathrm{kg}$, and 29.0 to $42.8 \mu \mathrm{g} / \mathrm{kg}$ on average. Gas chromatography coupled with mass spectrometry (GC-MS)-based metabolomics, in combination with multivariate analysis, revealed that 15 metabolites differentially accumulated when comparing green and conventional rice. Among these, 12 metabolites showed a high accumulation in green rice, including seven amino acids, two sugars, and three fatty acids. Overall, our results suggest the superior quality of a type of green rice that is popular in China, which may boost green rice consumption and facilitate the further expansion of green rice production in China.
\end{abstract}

Keywords: chinese green food; rice; physicochemical properties; elements; metabolomics

\section{Introduction}

Rapid economic growth in China has been accompanied by the increasing concern of consumers with respect to food quality and safety. In China, there are three levels of certification systems for food, which is indicative of the stringency of the associated standards, namely safe food, green food, and organic food [1]. Green food was first introduced by the Ministry of Agriculture of China in 1990, and it refers to a unique Chinese certification scheme for food, which indicates that the food was produced in accordance with the principle of sustainable development and that standard operational protocols were applied throughout the whole industry chain, as designated by the China Green Food Development Center (CGFDC) [2]. Green food, which is of a relatively lower standard compared with organic food, provides a "middle way" between safe and organic food and is widely accepted in China [3]. At the end of 2019, China already had 13,202 green-certified enterprises, representing 36,345 products and 21.7 million farmers, with 11.1 million hectares being used for the production of 157 million tons of green products. The annual sales and export values were Chinese Yuan (RMB) 455.7 billion yuan and USD 3.21, accounting for $8.20 \%$ of the total farmland area in China, and 9.7\% of the GDP was from agriculture [4]. 
Rice is one of the most important staple cereal foods for half of the world's population. In order to ensure food security, many countries frequently apply greater amounts of chemical fertilizers than required. The average rate of applied nitrogen $(\mathrm{N})$ fertilizer was $180 \mathrm{~kg} \mathrm{~N} / \mathrm{ha}$ for rice in China, which is $75 \%$ higher than the world average [5]. The application of excessive nitrogen fertilizer is a serious problem in China, which can not only decrease the grain yield and quality, but has also caused serious environmental problems [6-8]. Nitrogen fertilization is the most important factors for effectively improving rice yield and quality [9-11]. Recently, many optimized nutrient management strategies have been applied in China to improve rice yield and quality [12-14]. The combined application of an organic fertilizer with a chemical fertilizer is an important approach for increasing fertilizer use efficiency and soil microbial activity, which can improve the yield and quality of rice $[15,16]$. In the specific case of green-certified production, the application of chemical nitrogen fertilizer has been reduced by $50 \%$ compared with local farmers, and its use in combination with organic fertilizers is encouraged, since they are better able to meet the quality and safety demands of customers [4].

Rice comprises the largest proportion of green food products and accounts for $14.9 \%$. According to statistics, the yearly output yield of green-certified rice is 15.6 million tons, which was $7.4 \%$ of the total output of the nation in 2019 (CGFDC). The most important at-attitudinal factors relating to consumers' choice of green food include health concerns, environmental concerns, and taste preferences [17]. To date, studies on green food have mainly focused on the environment, economic yields, and consumers' willingness to pay $[1,2,18-20]$. Rice quality largely determines competitiveness in China. However, consumers are poorly informed about the quality of green food, though the difference in quality between green and conventional rice remains largely unclear. Thus, scientific evidence in support of the benefits of green foods is greatly needed to promote consumer confidence in such foods.

Wuchang is a city located in the northeast of China, and it is an important rice growing area with natural conditions that are excellent for this purpose. Wuchang rice has be-come extremely popular and well-known and is associated with high quality rice in China [21]. The brand Wuchang rice was valued at more than 69.8 billion yuan in 2020, ranking at number one among rice brands in China (National Bureau of Statistics). Daohuaxiang 2 (Oryza sativa ssp. japonica cv. Daohuaxiang 2) is predominantly grown in Wuchang city, Heilongjiang Province. Thus, Daohuaxiang 2 was selected for this study. The aim of the present study was to investigate and compare the nutritional quality of green labelled (hereafter referred to as "green rice") and conventional rice. To the best of our knowledge, no papers comparing the quality of green and conventional rice have been published. This paper reports the first study investigating the effects of green versus conventional agricultural practices on rice quality. It is expected that the information obtained in the present study could provide insights into green food in China and help consumers be better informed about green food, thus, promoting consumer confidence.

\section{Materials and Methods}

\subsection{Samples}

Twenty commercially available Daohuaxiang 2 rice samples, including ten greencertified and ten conventional rice samples, were purchased from a local Beijing supermarket. According to the selection criteria, the same variety (Daohuaxiang 2) and representative brands available at the time of sampling were selected as the experimental materials (Supplementary Materials Table S1). All of the green rice samples were certified by the China Green Food Development Center. The rice samples were ground into fine powder and sieved through a 55-mesh count screen, and the powder was stored at $-80^{\circ} \mathrm{C}$ until use.

\subsection{Chemicals and Reagents}

High-performance liquid chromatography (HPLC)-grade methanol, acetonitrile, dichloromethane, and water were obtained from Fisher Scientific (Pittsburgh, PA, USA). 
Formic acid of HPLC grade was purchased from TIC (Tokyo, Japan). Bis (trimethylsilyl) trifluoroacetamide (BSTFA), trimethylchlorosilane (TMCS), adonitol, nitric acid, acetic acid, and perchloric acid were obtained from Sigma Aldrich (St. Louis, MO, USA).

\subsection{Physicochemical and Rheological Properties}

The thousand kernel weight (TKW) of green and conventional rice was determined in triplicate based on randomly selected kernels that were weighed using an electrical balance. The bulk density was calculated as the ratio of milled rice grains to their volume and is reported as $\mathrm{g} / \mathrm{mL}$. The chalkiness degree was assessed according to the method of the China National Standard NY/T 593-2013. The moisture, protein, and fat content were analyzed by near-infrared (NIR) spectroscopy (FOSS-NIRSDS 2500, FOSS Analytical, Hoganas, Sweden). The determination of amylose was carried out calorimetrically using the amylose-iodine reaction. The amylose content was calculated using mixed standards of amylose and amylopectin [22]. The peak viscosity, final viscosity, breakdown viscosity, setback viscosity, peak time, and pasting temperature were measured using a Rapid Visco Analyzer (Perten RVA 4500, Segeltorp, Sweden) to evaluate the rheological properties of the starch structure, according to the manufacturer's instructions.

\subsection{Elemental Analysis}

The elements in rice were determined using the method described in a previous report [23]. In brief, $500 \mathrm{mg}$ rice samples were placed in a polytetrafluoroethylene (PTFE) digestion container. Nitric acid $(6 \mathrm{~mL})$ was added to each container and predigested overnight at $60^{\circ} \mathrm{C}$. Hydrogen peroxide $(2 \mathrm{~mL})$ was added after cooling. The heating program was performed in three steps. In the first step, the temperature was increased linearly to $120^{\circ} \mathrm{C}$ over a period of $6 \mathrm{~min}$ and maintained for $2 \mathrm{~min}$. In the second step, the temperature was increased linearly to $160{ }^{\circ} \mathrm{C}(1500 \mathrm{~W})$ over a period of $4 \mathrm{~min}$ and maintained for $8 \mathrm{~min}$. For the third step, the temperature was increased linearly to $180{ }^{\circ} \mathrm{C}$ $(1500 \mathrm{~W})$ over a period of $3 \mathrm{~min}$ and maintained for $20 \mathrm{~min}$, followed by $30 \mathrm{~min}$ of cooling. The essential elements in the rice were determined by inductively coupled plasma-atomic emission spectrometry (ICP-AES) using the Optima 7300DV (Perkin Elmer, Waltham, CO, USA), and the toxic elements were determined using a 7700 Series $\times$ ICP-MS (Agilent Technologies, Courtaboeuf, France).

\subsection{Non-Targeted Metabolomics Analysis}

Metabolomic analysis using gas chromatography coupled with mass spectrometry (GC-MS) was performed according to a previous report, with slight modifications [24]. First, $100 \mathrm{mg}$ rice powder was added into $1.0 \mathrm{~mL}$ water-methanol-dichloromethane solution (1:3:1) and $40 \mu \mathrm{L}$ internal standard solution $(200 \mu \mathrm{g} / \mathrm{mL}$, adonitol). The extraction was carried out by sonication for $30 \mathrm{~min}$, and the mixture was then centrifuged for $10 \mathrm{~min}$ at $16,000 \times g$. Next, $0.7 \mathrm{~mL}$ of the upper layer solution was transferred to a $1.5 \mathrm{~mL}$ Eppendorf tube and vacuum-dried in a CentriVap centrifugal vacuum concentrator (Labconco, Kansas City, MO, USA). Sixty microliters of methoxyamine hydrochloride $(20 \mathrm{mg} / \mathrm{mL}$ in pyridine) was added to each vial and incubated for $30 \mathrm{~min}$ at $80^{\circ} \mathrm{C}$. Subsequently, $80 \mu \mathrm{L}$ BSTFA reagent $(1 \%$ TMCS, $v / v)$ was added, followed by a reaction time of $1.5 \mathrm{~h}$ at $70^{\circ} \mathrm{C}$. GC-MS analysis was conducted using an Agilent 7890 gas chromatograph (Agilent Technologies, Palo Alto, CA, USA) system equipped with a Shimadzu GC-MS QP2010 Plus (Shimadzu, Kyoto, Japan). The instrumental settings followed previous protocols [24].

\subsection{Data Processing and Multivariate Data Analysis}

Tentative identification of metabolites was achieved using National Institute of Standards and Technology (NIST) 15 standard mass spectral databases (NIST, Gaithersburg, MD, USA) with a similarity of more than $80 \%$, verified by available reference compounds. Peak areas were normalized to the internal standard and exported to MS Office Excel (version 2019, Microsoft Corporation., Redmond, WA, USA). Principal component analy- 
sis (PCA) and partial least squares-discriminant analysis (PLS-DA) was conducted using SIMCA-P + software (version 14.0, Umertrics, Umea, Sweden). Statistical analysis was conducted using the SPSS statistical software (version 21; SPSS Corp., Chicago, IL, USA). The Student's $t$-test was performed to analyze significance of cross-group difference, and $p$ values lower than 0.05 indicated statistical significance.

\section{Results and Discussion}

\subsection{Physicochemical and Rheological Properties}

3.1.1. Physical Properties

The physical properties, including the thousand kernel weight, bulk density, chalkiness, and percentage of chalky kernels, of the green and conventional rice are reported in Table 1. The thousand kernel weight of rice is an important parameter for the evaluation of rice yield, and green rice showed a significantly higher thousand kernel weight (21.08 g) compared to that of conventional rice $(20.21 \mathrm{~g})$. No significant difference in bulk was observed between the green and conventional rice groups. Chalky rice kernels usually cause low eating quality and strongly influence consumer acceptance of products [25]. Green rice had a relatively lower chalkiness $(8.31 \%)$ and percentage of chalky kernels (22.46\%) than conventional rice $(9.74 \%$ and $26.15 \%$, respectively).

Table 1. Physicochemical properties of rice grains produced by the green food and conventional systems.

\begin{tabular}{ccc}
\hline Parameters & Green Rice & Conventional Rice \\
\hline Thousand kernel weight $(\mathrm{g})$ & $21.08 \pm 3.23 \mathrm{a}$ & $20.21 \pm 3.11 \mathrm{~b}$ \\
Bulk density $(\mathrm{g} / \mathrm{mL})$ & $0.98 \pm 0.12 \mathrm{a}$ & $0.96 \pm 0.09 \mathrm{a}$ \\
Chalkiness $(\%)$ & $8.31 \pm 1.47 \mathrm{~b}$ & $9.94 \pm 2.26 \mathrm{a}$ \\
Percentage of chalky kernels & $22.46 \pm 5.06 \mathrm{~b}$ & $26.15 \pm 3.43 \mathrm{a}$ \\
Moisture content $(\mathrm{g} / 100 \mathrm{~g})$ & $11.65 \pm 0.23 \mathrm{a}$ & $11.53 \pm 0.31 \mathrm{a}$ \\
Protein $(\mathrm{g} / 100 \mathrm{~g})$ & $7.11 \pm 0.56 \mathrm{~b}$ & $7.42 \pm 0.71 \mathrm{a}$ \\
Fat content $(\mathrm{g} / 100 \mathrm{~g})$ & $0.80 \pm 0.12 \mathrm{a}$ & $0.77 \pm 0.13 \mathrm{a}$ \\
Amylose content $(\mathrm{g} / 100 \mathrm{~g})$ & $17.2 \pm 0.82 \mathrm{a}$ & $16.3 \pm 0.91 \mathrm{~b}$ \\
\hline Values $( \pm$ standard deviation) within the same row followed by "a" are significantly higher than those indicated \\
by " $\mathrm{b}$ " $(p<0.05)(n=3)$.
\end{tabular}

Most inspection guides for rice use chalkiness and the percentage of chalky kernels for grading. The chalky grain rate of first-grade high-quality rice is lower than $10 \%$, while that of inferior rice is higher than $30 \%$ in China [26]. Chalkiness is a complex polygenic trait, and nitrogen fertilizers had significant effects on the chalky trait of rice grain. Many studies have reported that nitrogen fertilization significantly increased the percentage of chalky kernels and chalkiness $[9,27,28]$. Thus, the chalky trait of rice from different production systems may be due to the management of different fertilizers. The adoption of green food production systems, with combined application of organic and inorganic fertilizers, is advisable as a good compromise for chalky rice [6].

\subsubsection{Main Chemical Components}

The main chemical components of green and conventional rice are shown in Table 1. Protein content is a crucial factor in rice quality. In the present study, green rice exhibited a lower protein content $(7.11 \mathrm{~g}$ per $100 \mathrm{~g}$ ) in comparison to conventional rice $(7.42 \mathrm{~g}$ per $100 \mathrm{~g})$. Amylose content is also an important factor for estimating the cooking or eating quality of rice. Table 1 shows that the amylose content in green rice was higher than in conventional rice. Moisture and fat contents greatly affect the quality of rice. In this study, the results showed no significant difference in moisture and fat contents between the green and conventional rice.

Previous studies have reported that the protein content is negatively correlated to the palatability of rice [29-31]. Many studies have reported that a high protein content is associated with a harder cooked rice and may influence its eating quality [32,33]. Similar findings have been reported in an organic rice cropping system, with organic rice showing a 
lower accumulation of protein than conventional rice [34,35]. It has been observed that the application of a nitrogen fertilizer significantly increases the protein content of rice $[27,36]$. Previously, a study reported that the combined application of $40 \%$ organic fertilizer and $60 \%$ chemical fertilizer was the optimal ratio for obtaining the best quality of rice [37].

Low-amylose rice is generally soft and sticky after cooking, whereas high-amylose rice is harder and less sticky. This result, in accordance with previous results, indicate that organic rice shows a higher amylose content than conventional rice [34,38]. A higher amylose content may be associated with fertilizer application. Iqbal et al. reported that the use of an organic fertilizer combined with a chemical fertilizer considerably improved the rice amylase content [39].

\subsubsection{Rheological Properties}

The pasting properties, as determined by RVA, are widely accepted indicators for the critical and rapid assessment of the eating and cooking quality of rice [40]. The peak viscosity, final viscosity, breakdown viscosity, and setback viscosity of the green rice and conventional rice are shown in Table 2 . The present study shows that the pasting properties of the green rice and conventional rice were significantly different $(p<0.05)$. Peak viscosity is an indicator of water-binding capacity. The peak viscosity of green rice ranged from 3625 to 4463 centipoise (cP), with a mean value of $4250 \mathrm{cP}$, while for conventional rice, this ranged from 3417 to $4325 \mathrm{cP}$, with a mean value of $4055 \mathrm{cP}$. The final viscosity indicates the ability of the starch to obtain a gel structure after cooking and cooling. The final mean viscosity value of $4353 \mathrm{cP}$ for green rice was high compared to that of conventional rice. Breakdown viscosity is associated with the ease of cooking rice starch, and this value for green rice $(1526 \mathrm{cP})$ was higher than that of conventional rice $(1478 \mathrm{cP})$, but this difference was statistically insignificant $(p=0.5231)$. Setback viscosity indicates the rate of starch retrogradation, and green rice was found to have lower rates of starch retrogradation compared with conventional rice.

Table 2. Pasting properties of rice starch obtained from green rice (GR) and conventional rice (CR) systems.

\begin{tabular}{ccc}
\hline Parameters & GR & CR \\
\hline Peak viscosity $(\mathrm{cP})$ & $4250 \pm 371 \mathrm{a}$ & $4055 \pm 411 \mathrm{~b}$ \\
Final viscosity $(\mathrm{cP})$ & $4353 \pm 324 \mathrm{a}$ & $4132 \pm 321 \mathrm{~b}$ \\
Breakdown viscosity $(\mathrm{cP})$ & $1526 \pm 142 \mathrm{a}$ & $1478 \pm 156 \mathrm{a}$ \\
Setback viscosity $(\mathrm{cP})$ & $1011 \pm 179 \mathrm{~b}$ & $1231 \pm 165 \mathrm{a}$ \\
\hline Values $( \pm$ standard deviation) within the same row followed by "a" are significantly higher than those indicated \\
by "b" $(p<0.05)(n=3)$.
\end{tabular}

Cooking quality is an important attribute with respect to consumers' acceptance, and has been found to vary significantly for rice depending on the cultivation system. Overuse of $\mathrm{N}$ fertilizers leads to poor eating and cooking quality of the grain [12]. The pasting properties were negatively correlated with the protein content [41]. The green rice with good taste values showed a higher peak viscosity and final viscosity, by contrast, with a lower setback viscosity. A higher peak, final, and setback viscosity was reported in organic rice compared to the conventional product $[35,41]$. Nonetheless, our study suggested that the cooking and eating quality of green rice was significantly improved due to the adoption of green rice management practice.

\subsection{Elemental Signatures of Green and Conventional Rice}

\subsubsection{Toxic Elements}

Four toxic elements of the rice samples were analyzed (Figure 1). Chromium (Cr) is considered a serious environmental pollutant due to its wide industrial applications. Evidence has demonstrated that $\mathrm{Cr}$ can pose serious health risks to humans, causing diarrhea, asthma, and cancer [42]. The Cr concentration in the green rice $(98.7 \mu \mathrm{g} / \mathrm{kg})$ was 
lower than that in the conventional rice $(180.1 \mu \mathrm{g} / \mathrm{kg})$, and the green rice ranged from $18.1-170.7 \mu \mathrm{g} / \mathrm{kg}$, while the range in the conventional rice was $150.4-226.3 \mu \mathrm{g} / \mathrm{kg}$.
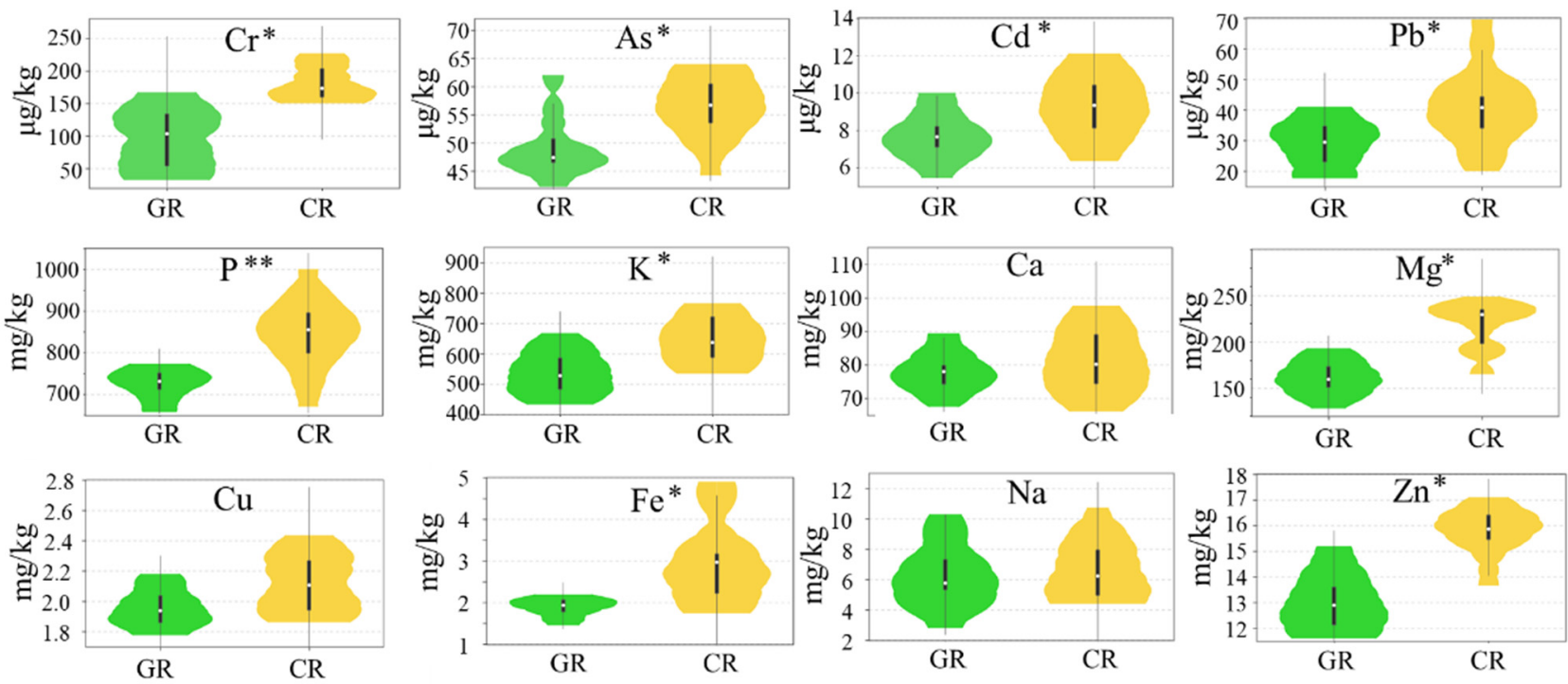

Figure 1. Violin plot of toxic elements and essential elements in the green rice (GR) and conventional rice (CR) systems $\left({ }^{*} p<0.05,{ }^{* *} p<0.005\right)$.

Arsenic (As) is a ubiquitous metalloid that can cause cancer in humans and enter the food chain mainly from contaminated drinking water [43]. Rice has been reported to contain a more toxic form of arsenic in comparison to other plants [44]. The As content of green rice $(42.2-60.7 \mu \mathrm{g} / \mathrm{kg})$ was lower than that of the conventional rice $(44.4-88.9 \mu \mathrm{g} / \mathrm{kg})$. The As content in this study can be considered low in comparison with that reported in other studies $[45,46]$.

Rice grains around the world are frequently contaminated with cadmium $(\mathrm{Cd})$, which poses a serious threat to human health and has attracted widespread concern [47]. The concentration of $\mathrm{Cd}$ in green rice is lower than that in conventional rice. Soil conditions and management practices can significantly influence the $\mathrm{Cd}$ content in rice. Previous studies have indicated that the application of organic fertilizer significantly reduces the $\mathrm{Cd}$ content in rice plants [48]. Green food reduces chemical nitrogen fertilizer use by $50 \%$ compared with the fertilization levels local farmers through supplementation with organic fertilizers [4]. The limit for $\mathrm{Cr}$ in rice established by the Ministry of Agriculture is $200 \mu \mathrm{g} / \mathrm{kg}$. Both types of rice showed very low levels of Cd content, which were well below the prescribed limit.

Lead $(\mathrm{Pb})$ is one of the more frequently studied elements in rice [44,49]. It has been reported that the mean concentration of $\mathrm{Pb}$ in rice collected in China is $100 \pm 140 \mu \mathrm{g} / \mathrm{kg}$ [50]. In this study, $\mathrm{Pb}$ was quantified at concentrations ranging from 17.6 to $40.9 \mu \mathrm{g} / \mathrm{kg}$ for green rice and from 20.1 to $80.6 \mu \mathrm{g} / \mathrm{kg}$ for conventional rice, values which are within the Ministry of Agriculture's maximum permissible limit for this metal $(200 \mu \mathrm{g} / \mathrm{kg})$.

\subsubsection{Essential Elements}

The levels of eight essential elements ( $\mathrm{P}, \mathrm{K}, \mathrm{Ca}, \mathrm{Mg}, \mathrm{Cu}, \mathrm{Fe}, \mathrm{Na}$, and $\mathrm{Zn}$ ) were determined in the rice samples. These micronutrients are important for human health, and a deficiency of these microelements can result in serious diseases. The ANOVA results of each element for the green and conventional rice showed that the $\mathrm{P}, \mathrm{K}, \mathrm{Mg}$, $\mathrm{Fe}$, and $\mathrm{Zn}$ levels were significantly different $(p$ values $<0.05)$. $\mathrm{P}$ and $\mathrm{K}$ were the most abundant essential elements in both types of rice, and the $\mathrm{P}$ contents of the green rice and conventional rice ranged from 657.3 to $772.0 \mathrm{mg} / \mathrm{kg}$ and 671.3 to $995.2 \mathrm{mg} / \mathrm{kg}$, respectively. For K, the content found in green rice ranged from 453.8 to $667.4 \mathrm{mg} / \mathrm{kg}$, which is lower than that in the conventional rice, which ranged from 535.1 to $739.5 \mathrm{mg} / \mathrm{kg}$. Both elements were 
significantly higher in conventional rice, which may be due to the fact that $\mathrm{P}$ and $\mathrm{K}$ are contained in synthetic fertilizer and are largely used in conventional rice farming.

$\mathrm{Mg}$ is an essential element for the human body. Many studies have reported that an $\mathrm{Mg}$ deficiency is associated with a wide range of diseases, including cardiovascular diseases, arrhythmia, osteoporosis, and fibromyalgia [51,52]. The Mg content of green rice $(128.1-192.7 \mathrm{mg} / \mathrm{kg}$ ) was lower that of conventional rice $(165.7-248.4 \mathrm{mg} / \mathrm{kg})$. A previous study reported synergistic behavior between the $\mathrm{Mg}$ and $\mathrm{K}$ concentrations [53].

The iron content of green rice ranged from 1.5 to $2.2 \mathrm{mg} / \mathrm{kg}$, while the range for conventional rice was between 1.7 to $4.9 \mathrm{mg} / \mathrm{kg}$. Previous studies have reported that the application of a nitrogen fertilizer promoted Fe accumulation in rice grain [54]. Iron deficiency was recently listed as a public health problem and the 6th leading cause of disease in developing countries by the World Health Organization (WHO) [55]. The amount of bioavailable iron in rice is low, and the phytic acid present in rice may inhibit the bioavailability of iron [56].

Likewise, the zinc $(\mathrm{Zn})$ concentrations in green rice ranged from 11.6 to $15.2 \mathrm{mg} / \mathrm{kg}$, while the concentration in conventional rice ranged from 13.7 to $17.1 \mathrm{mg} / \mathrm{kg}$. The mean zinc content in green rice was $13.3 \mathrm{mg} / \mathrm{kg}$, and the mean value in conventional rice was $15.3 \mathrm{mg} / \mathrm{kg}$. $\mathrm{Zn}$ is one of the most essential elements required for the growth of human beings. The relatively low $\mathrm{Zn}$ concentrations found in both types of rice cannot meet the daily dietary requirement [57].

The results of the present study indicate the importance of management practice in contributing to rice element accumulation. Concentrations of all examined toxic $(\mathrm{Cr}$, $\mathrm{As}, \mathrm{Cd}$, and $\mathrm{Pb}$ ) and essential elements $(\mathrm{P}, \mathrm{K}, \mathrm{Mg}, \mathrm{Fe}$, and $\mathrm{Zn}$ ) in green rice were lower compared to those of conventional rice. Chemical fertilizers promote the absorption of more elements from the soil by the rice. There were no significant differences found in $\mathrm{Ca}$, $\mathrm{Cu}$, and $\mathrm{Na}$ between the green and conventional rice. The synthetic N, P, and $\mathrm{K}$ compound fertilizers are applied at high concentrations in conventional rice, so the associated elements are accumulated at higher levels. With strict regulations and regular inspection, green rice contained significantly lower levels of toxic elements than conventional rice. These results are useful as scientific evidence of the greater safety of green rice in comparison with conventional rice in terms of toxic metal levels. In a study by Xiao et al. in China, the range of $\mathrm{Cr}, \mathrm{As}, \mathrm{Cd}$, and $\mathrm{Pb}$ contents in rice increased from 0 to $200 \mu \mathrm{g} / \mathrm{kg}, 100$ to $200 \mu \mathrm{g} / \mathrm{kg}$, 0 to $150 \mu \mathrm{g} / \mathrm{kg}$, and 0 to $100 \mu \mathrm{g} / \mathrm{kg}$, respectively [58]. When comparing these results with ours (Figure 1), all of the toxic elements are well within the acceptable range. Indeed, $\mathrm{Cd}$ was much lower than the average in China, which may be due to the low $\mathrm{Cd}$ accumulation in the soil in northern China compared to the other areas [59]. Additionally, the content of toxic elements in both types of rice was well below the prescribed limit, indicating that the twenty brands of rice sold in Beijing markets can be considered as very safe. Consumer demand for healthier and safer rice that contains a lower content of toxic elements is growing. In our study, green rice was demonstrated to be safer than conventional rice. However, it is also worth noting that the levels of essential elements were observed to be lower in green rice than in conventional rice, suggesting that greater efforts should be made toward improving the content of essential elements in green rice by biofortification in the future.

\subsection{Untargeted Metabolomics}

Untargeted metabolomics was used to provide comprehensive information for comparing green rice and conventional rice. In this study, the metabolites from rice grains were identified by GC-MS. Metabolite identification was performed through a comparison of the results with authentic standards, fragmentation patterns, and database references. In total, 64 metabolites, including amino acids, organic acids, sugars, sugar alcohols, and amines, were identified in the rice samples. The relative intensities were normalized based on the intensities of the internal standards and were used to perform multivariate statistical analyses. PCA and PLS-DA were used to analyze the metabolomics datasets for green and 
conventional rice. The PCA score plots exhibited clear differentiations between the green and conventional rice for PC1 (28.1\%) and PC2 (12.2\%) (Supplementary Materials Figure S1). A similar separation pattern was observed using PLS-DA, including $23.8 \%$ of the first and $15.3 \%$ of the second principal components (Figure 1), and 15 significantly different metabolites were selected, with a variable importance for projection (VIP) $>1.0$ and $p<0.05$ (Figure 2). These significant differing metabolites served as characteristic compounds that could be used for differentiating green rice and conventional rice.

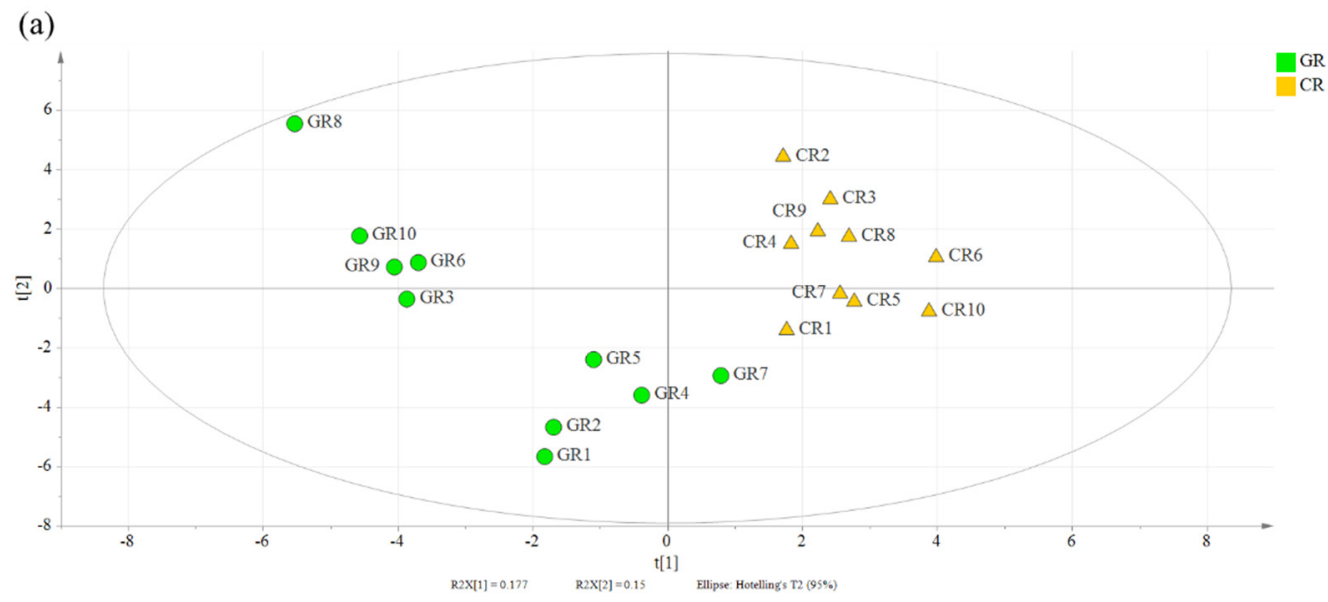

(b)

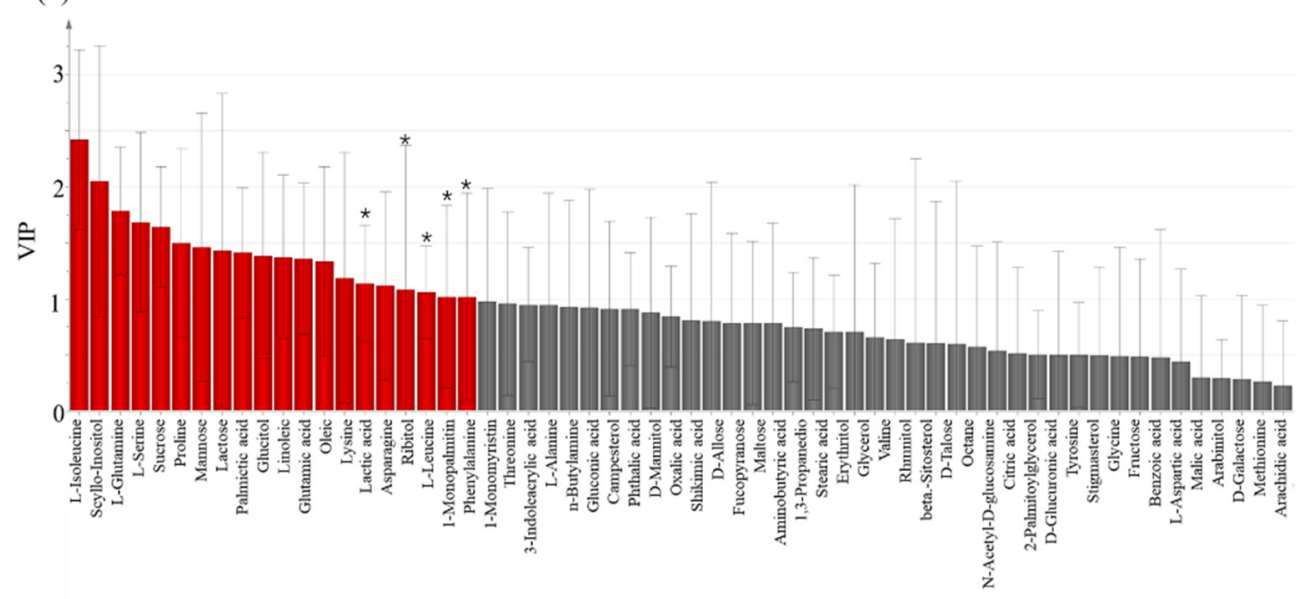

Figure 2. Partial least squares-discriminant analysis (PLS-DA) score plot (a) of primary metabolites identified by GC-MS. (b) Metabolites (b) that were differentially expressed between GR (green rice) and CR (conventional rice) with a VIP > 1.0 were considered significant. * denotes $p>0.05$ (insignificant).

The 15 differential metabolites included seven amino acids, five sugars, and three fatty acids. The heatmap shows the abundance of metabolites in different clusters from each sample (Figure 3). In green rice, seven (proline, serine, asparagine, lysine, threonine, L-glutamine, and L-isoleucine) out of 18 amino acids accumulated to significantly higher levels than in conventional rice. Sugars are important for the taste and quality of the grain. Sucrose and lactose were found to be highly expressed in green rice. In contrast, higher levels of myo-inositol, mannose, and glucitol were found in green rice compared to the conventional rice. Three fatty acids, including oleic, linoleic, and palmitic acid, were significantly differentially expressed between the green and conventional rice, with expression higher in green rice. 


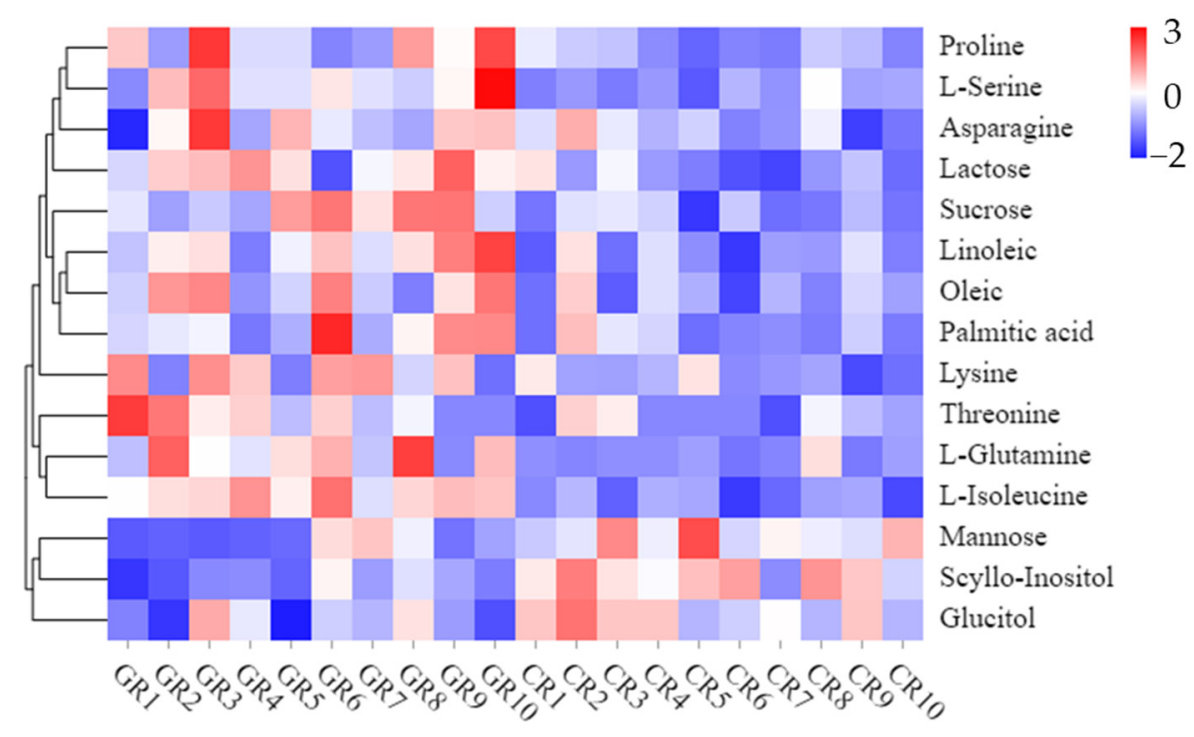

Figure 3. Heatmap of fifteen key metabolites differentially expressed between green and conventional rice. Note: $\mathrm{GR}=$ green rice, $\mathrm{CR}$ = conventional rice. The more intense red color indicates a higher level of metabolite expression; the more intense blue color indicates a lower level of metabolite expression.

The results of untargeted metabolomics in this study revealed that the metabolic variations between green and conventional rice were significantly different. Amino acids are essential nutritional components in rice. The difference in amino acid contents between green and conventional rice may be due to their different production systems. The green rice was produced with a limited amount of chemical fertilizers in combination with organic fertilizers. In a previous study, the combined application of organic and chemical fertilizers significantly increased the nitrogen use efficiency, soil matter, microbial activity in the soil, and rice yield $[15,16,60]$. Significantly increased total essential amino acid contents have also been found when using combined chemical and organic fertilizers [61,62]. However, organic rice has shown a lower or similar level of amino acids than conventional rice $[63,64]$. 15N-labeled tracer techniques showed that combined application of chemical and organic fertilizers significantly increased the percentages of organic $\mathrm{N}$ and amino acid $\mathrm{N}$ [65]. The release of $\mathrm{N}$ from organic fertilizers partially contributed to increased amino acid accumulation.

We noted that the contents of sucrose and lactose were significantly higher in green rice than in conventional rice, with $p$-values of less than 0.001 . It was reported that nitrogen overfertilization significantly inhibited sugar biosynthesis and lower its accumulation with the application of K [66]. However, three other sugars, including myo-inositol, mannose, and glucitol, were present in higher amounts in conventional rice compared to green rice. The reason for this phenomenon remains unanswered at present. Oleic, linoleic, and palmitic acid are the major fatty acids, accounting for more than $90 \%$ of the total fatty acids in rice [67]. All of the three fatty acids were significantly higher in the green rice than in the conventional rice, and this is an important consideration for future research. Fatty acids are highly associated with fungi, and the addition of organic fertilizers significantly increased the fungal population [68]. It has been reported that these fatty acids contribute to the prevention of several diseases, such as cardiovascular disease, inflammatory disease, and cancer [69].

In our study, most metabolites were highly accumulated in green rice. Most probably, the production systems of green rice involved chemical fertilizers combined with organic fertilizers, which can improve the utilization rate of fertilizers and the microbial activities in soil and alter metabolic pathways to certain extent within the plant, thus, enhancing the accumulation of beneficial metabolites in rice. 


\section{Conclusions}

Currently, the growing concern of consumers as regards food safety and the environment is gaining strength. The current agricultural system in China heavily depends on the use of chemical $\mathrm{N}$, which negatively affects $\mathrm{N}$ use efficiency and soil health, the environment, and food safety. This paper investigated and compared the quality and metabolomics of rice grown in green-certified versus conventional production systems. The physicochemical and rheological properties were higher for rice grown under the green-certified system than under the conventional farming system. The toxic elements in both types of rice were very low, indicating that the investigated rice sold in Beijing markets can be regarded as very safe, although the green rice was found to be safer than the conventional rice, as it had a lower toxicity. However, the essential elements ( $\mathrm{P}, \mathrm{K}$, $\mathrm{Mg}, \mathrm{Fe}$, and $\mathrm{Zn}$ ) were present at lower levels in green rice compared with conventional rice. Through untargeted metabolomics analysis using GC-MS, we found that 15 of the 64 detected metabolites were more highly expressed in green rice, and three metabolites were more highly expressed in the conventional rice. The differences between the two types of rice in terms of metabolites may be mainly due to the reductions in the use of synthetic fertilizers and the combined use of organic and chemical fertilizers. Thus, the green rice production system is a potential alternative to the conventional system, which allows for a reduction in chemical fertilizer use, producing safer rice of a higher quality and, thus, is financially attractive to farmers. The results of this study could be useful in the further development of green rice production in China.

Supplementary Materials: The following are available online at https://www.mdpi.com/article/10 .3390/foods10050915/s1, Table S1: The information of rice samples from green rice and conventional rice. Figure S1: PCA score plots derived from non-targeted metabolite profiling of three different treatments analyzed by GC-MS.

Author Contributions: Conceptualization, J.X.; methodology, J.X.; software, J.X.; validation, J.X.; formal analysis, J.X.; investigation, J.X., J.Z. and B.Z.; resources, J.X.; data curation, J.X.; writingoriginal draft preparation, J.X.; writing-review and editing, X.L.; visualization, X.L.; supervision, X.L.; project administration, J.X.; funding acquisition, J.X. All authors have read and agreed to the published version of the manuscript.

Funding: This study was supported by the National Science Foundation of China (No. 31501832 and No. 31902121) and Meng Hai Man Xiang Yun Tian Agricultural Company (No. MXYTSC20200409).

Institutional Review Board Statement: Not applicable.

Informed Consent Statement: Not applicable.

Data Availability Statement: Data is contained within the article or Supplementary Materials.

Conflicts of Interest: The authors declare no conflict of interest.

\section{References}

1. Yu, X.H.; Gao, Z.F.; Zeng, Y.C. Willingness to pay for the "Green Food" in China. Food Policy 2014, 45, 80-87. [CrossRef]

2. Qi, X.; Ploeger, A. Explaining consumers' intentions towards purchasing green food in Qingdao, China: The amendment and extension of the theory of planned behavior. Appetite 2019, 133, 414-422. [CrossRef] [PubMed]

3. Lin, L.; Zhou, D.Y.; Ma, C.X. Green food industry in China: Development, problems and policies. Renew. Agric. Food Syst. 2010, 25, 69-80. [CrossRef]

4. Xu, J.L.; Zhang, Z.H.; Zhang, X.; Ishfaq, M.; Zhong, J.H.; Li, W.; Zhang, F.S.; Li, X.X. Green Food Development in China: Experiences and Challenges. Agriculture 2020, 10, 614. [CrossRef]

5. Peng, S.B.; Tang, Q.Y.; Zou, Y.B. Current Status and Challenges of Rice Production in China. Plant Prod. Sci. 2009, 12, 3-8. [CrossRef]

6. Zhang, H.; Hou, D.P.; Peng, X.L.; Ma, B.J.; Shao, S.M.; Jing, W.J.; Gu, J.F.; Liu, L.J.; Wang, Z.Q.; Liu, Y.Y.; et al. Optimizing integrative cultivation management improves grain quality while increasing yield and nitrogen use efficiency in rice. J. Integr. Agric. 2019, 18, 2716-2731. [CrossRef]

7. Clark, C.M.; Tilman, D. Loss of plant species after chronic low-level nitrogen deposition to prairie grasslands. Nature 2008, 451, 712-715. [CrossRef] [PubMed] 
8. Wu, M.; Liu, M.; Liu, J.; Li, W.T.; Jiang, C.Y.; Li, Z.P. Optimize nitrogen fertilization location in root-growing zone to increase grain yield and nitrogen use efficiency of transplanted rice in subtropical China. J. Integr. Agric. 2017, 16, 2073-2081. [CrossRef]

9. Tang, S.; Zhang, H.X.; Liu, W.Z.; Dou, Z.; Zhou, Q.Y.; Chen, W.Z.; Wang, S.H.; Ding, Y.F. Nitrogen fertilizer at heading stage effectively compensates for the deterioration of rice quality by affecting the starch-related properties under elevated temperatures. Food Chem. 2019, 277, 455-462. [CrossRef] [PubMed]

10. Sano, O.; Ito, T.; Saigusa, M. Effects of co-situs application of controlled-availability fertilizer on fertilizer and soil nitrogen uptake by rice (Oryza sativa L.) in paddy soils with different available nitrogen. Soil Sci. Plant Nutr. 2008, 54, 769-776. [CrossRef]

11. Perez, C.M.; Juliano, B.O.; Liboon, S.P.; Alcantara, J.M.; Cassman, K.G. Effects of late nitrogen fertilizer application on head rice yield, protein content, and grain quality of rice. Cereal Chem. 1996, 73, 556-560.

12. Peng, S.B.; Buresh, R.J.; Huang, J.L.; Zhong, X.H.; Zou, Y.B.; Yang, J.C.; Wang, G.H.; Liu, Y.Y.; Hu, R.F.; Tang, Q.Y.; et al. Improving nitrogen fertilization in rice by site-specific N management. A review. Agron. Sustain. Dev. 2010, 30, 649-656. [CrossRef]

13. Peng, S.B.; Buresh, R.J.; Huang, J.L.; Zhong, X.H.; Zou, Y.B.; Yang, J.C.; Wang, G.H.; Liu, Y.Y.; Hu, R.F.; Tang, Q.Y.; et al. Improving nitrogen fertilization in rice by site-specific N management. Sustain. Agric. 2011, 2, 943-952.

14. Ding, W.C.; Xu, X.P.; He, P.; Ullah, S.; Zhang, J.J.; Cui, Z.L.; Zhou, W. Improving yield and nitrogen use efficiency through alternative fertilization options for rice in China: A meta-analysis. Field Crop. Res. 2018, 227, 11-18. [CrossRef]

15. Xu, M.-G.; Li, D.-C.; Li, J.-M.; Qin, D.Z.; Kazuyuki, Y.; Hosen, Y. Effects of organic manure application with chemical fertilizers on nutrient absorption and yield of rice in Hunan of Southern China. Agric. Sci. China 2008, 7, 1245-1252. [CrossRef]

16. Naher, U.A.; Panhwar, Q.A.; Othman, R.; Ismail, M.R.; Berahim, Z. Biofertilizer as a supplement of chemical fertilizer for yield maximization of rice. J. Agric. Food Devel. 2016, 2, 16-22. [CrossRef]

17. Custodio, M.C.; Cuevas, R.P.; Ynion, J.; Laborte, A.G.; Velasco, M.L.; Demont, M. Rice quality: How is it defined by consumers, industry, food scientists, and geneticists? Trends Food Sci. Technol. 2019, 92, 122-137. [CrossRef]

18. Liu, R.F.; Gao, Z.F.; Yan, G.A.; Ma, H.Y. Why should we protect the interests of "Green Food" certified product growers? Evidence from kiwifruit production in China. Sustainability 2018, 10, 4797. [CrossRef]

19. Wang, F.; Liu, Y.X.; Ouyang, X.H.; Hao, J.Q.; Yang, X.S. Comparative environmental impact assessments of green food certified cucumber and conventional cucumber cultivation in China. Renew. Agric. Food Syst. 2018, 33, 432-442. [CrossRef]

20. Tong, Q.; Anders, S.; Zhang, J.; Zhang, L. The roles of pollution concerns and environmental knowledge in making green food choices: Evidence from Chinese consumers. Food Res. Int. 2020, 130, 108881. [CrossRef]

21. Song, H.; Lu, B.; Ye, C.; Li, J.; Zhu, Z.; Zheng, L. Fraud vulnerability quantitative assessment of Wuchang rice industrial chain in China based on AHP-EWM and ANN methods. Food Res. Int. 2020, 140, 109805. [CrossRef] [PubMed]

22. Reddy, C.K.; Luan, F.; Xu, B.J. Morphology, crystallinity, pasting, thermal and quality characteristics of starches from adzuki bean (Vigna angularis L.) and edible kudzu (Pueraria thomsonii Benth). Int. J. Biol. Macromol. 2017, 105, 354-362. [CrossRef] [PubMed]

23. Fu, J.; Zhou, Q.; Liu, J.; Liu, W.; Wang, T.; Zhang, Q.; Jiang, G. High levels of heavy metals in rice (Oryzasativa L.) from a typical E-waste recycling area in southeast China and its potential risk to human health. Chemosphere 2008, 71, 1269-1275. [CrossRef] [PubMed]

24. Xu, J.L.; Wu, L.Q.; Tong, B.X.; Yin, J.X.; Huang, Z.C.; Li, W.; Li, X.X. Magnesium supplementation alters leaf metabolic pathways for higher flavor quality of Oolong tea. Agriculture 2021, 11, 120. [CrossRef]

25. Jittanit, W.; Angkaew, K. Effect of superheated-steam drying compared to conventional parboiling on chalkiness, head rice yield and quality of chalky rice kernels. J. Stored Prod. Res. 2020, 87, 1-16. [CrossRef]

26. Wu, Q.; Wang, Y.Z.; Chen, T.T.; Zheng, J.L.; Sun, Y.D.; Chi, D.C. Soil nitrogen regulation using clinoptilolite for grain filling and grain quality improvements in rice. Soil Tillage Res. 2020, 199, 104547. [CrossRef]

27. Gu, J.F.; Chen, J.; Chen, L.; Wang, Z.Q.; Zhang, H.; Yang, J.C. Grain quality changes and responses to nitrogen fertilizer of japonica rice cultivars released in the Yangtze River Basin from the 1950s to 2000s. Crop J. 2015, 3, 285-297. [CrossRef]

28. Zhou, L.J.; Liang, S.S.; Ponce, K.; Marundon, S.; Ye, G.Y.; Zhao, X.Q. Factors affecting head rice yield and chalkiness in indica rice. Field Crop. Res. 2015, 172, 1-10. [CrossRef]

29. Balindong, J.L.; Ward, R.M.; Liu, L.; Rose, T.J.; Pallas, L.A.; Ovenden, B.W.; Snell, P.J.; Waters, D.L.E. Rice grain protein composition influences instrumental measures of rice cooking and eating quality. J. Cereal Sci. 2018, 79, 35-42. [CrossRef]

30. Martin, M.; Fitzgerald, M.A. Proteins in rice grains influence cooking properties. J. Cereal Sci. 2002, 36, 285-294. [CrossRef]

31. Leesawatwong, M.; Jamjod, S.; Kuo, J.; Dell, B.; Rerkasem, B. Nitrogen fertilizer increases seed protein and milling quality of rice. Cereal Chem. 2005, 82, 588-593. [CrossRef]

32. Baxter, G.; Blanchard, C.; Zhao, J. Effects of glutelin and globulin on the physicochemical properties of rice starch and flour. J. Cereal Sci. 2014, 60, 414-420. [CrossRef]

33. Baxter, G.; Zhao, J.A.; Blanchard, C. Albumin significantly affects pasting and textural characteristics of rice flour. Cereal Chem. 2010, 87, 250-255. [CrossRef]

34. Alves, G.H.; Paraginski, R.T.; Lamas, N.D.; Hoffmann, J.F.; Vanier, N.L.; de Oliveira, M. Effects of organic and conventional cropping systems on technological properties and phenolic compounds of freshly harvested and stored rice. J. Food Sci. 2017, 82, 2276-2285. [CrossRef] [PubMed]

35. Kaur, M.; Kaur, N.; Kaur, M.; Sandhu, K.S. Some properties of rice grains, flour and starches: A comparison of organic and conventional modes of farming. Lwt-Food Sci. Technol. 2015, 61, 152-157. [CrossRef] 
36. Gunaratne, A.; Sirisena, N.; Ratnayaka, U.K.; Ratnayaka, J.; Kong, X.L.; Arachchi, L.P.V.; Corke, H. Effect of fertiliser on functional properties of flour from four rice varieties grown in Sri Lanka. J. Sci. Food Agric. 2011, 91, 1271-1276. [CrossRef] [PubMed]

37. Zhou, J.M. Effect of combined application of organic and mineral fertilizers on yield, quality and nitrogen uptake of rice. J. Plant Nutr. Fertil. 2012, 18, 234-240.

38. Bagchi, T.B.; Ghosh, A.; Kumar, U.; Chattopadhyay, K.; Sanghamitra, P.; Ray, S.; Adak, T.; Sharma, S. Comparison of nutritional and physicochemical quality of rice under organic and standard production systems. Cereal Chem. 2016, 93, 435-443. [CrossRef]

39. Iqbal, A.; Xie, H.; He, L.; Ahmad, S.; Hussain, I.; Raza, H.; Khan, A.; Wei, S.; Quan, Z.; Wu, K.; et al. Partial substitution of organic nitrogen with synthetic nitrogen enhances rice yield, grain starch metabolism and related genes expression under the dual cropping system. Saudi J. Biol. Sci. 2021, 28, 1283-1296. [CrossRef]

40. Tong, C.; Chen, Y.L.; Tang, F.F.; Xu, F.F.; Huang, Y.; Chen, H.; Bao, J.S. Genetic diversity of amylose content and RVA pasting parameters in 20 rice accessions grown in Hainan, China. Food Chem. 2014, 161, 239-245. [CrossRef]

41. Kesarwani, A.; Chiang, P.Y.; Chen, S.S. Rapid visco analyzer measurements of japonica rice cultivars to study interrelationship between pasting properties and farming system. Int. J. Agron. 2016, 2016, 3595326. [CrossRef]

42. Yang, D.; Liu, J.C.; Wang, Q.; Hong, H.L.; Zhao, W.W.; Chen, S.; Yan, C.L.; Lu, H.L. Geochemical and probabilistic human health risk of chromium in mangrove sediments: A case study in Fujian, China. Chemosphere 2019, 233, 503-511. [CrossRef] [PubMed]

43. Jitaru, P.; Millour, S.; Roman, M.; El Koulali, K.; Noel, L.; Guerin, T. Exposure assessment of arsenic speciation in different rice types depending on the cooking mode. J. Food Compos. Anal. 2016, 54, 37-47. [CrossRef]

44. Londonio, A.; Morzan, E.; Smichowski, P. Determination of toxic and potentially toxic elements in rice and rice-based products by inductively coupled plasma-mass spectrometry. Food Chem. 2019, 284, 149-154. [CrossRef] [PubMed]

45. Fei, M.L.; Jin, Y.K.; Jin, L.; Su, J.; Ruan, Y.; Wang, F.; Liu, C.L.; Sun, C.X. Adaptation of rice to the nordic climate yields potential for rice cultivation at most northerly site and the organic production of low-arsenic and high-protein rice. Front Plant Sci. 2020, 11, 329. [CrossRef]

46. Islam, S.; Rahman, M.M.; Rahman, M.A.; Naidu, R. Inorganic arsenic in rice and rice-based diets: Health risk assessment. Food Control 2017, 82, 196-202. [CrossRef]

47. Ma, X.M.; Sharifan, H.; Dou, F.G.; Sun, W.J. Simultaneous reduction of arsenic (As) and cadmium (Cd) accumulation in rice by zinc oxide nanoparticles. Chem. Eng. J. 2020, 384, 123802. [CrossRef]

48. Han, C.L.; Wu, L.H.; Tan, W.N.; Zhong, D.X.; Huang, Y.J.; Luo, Y.M.; Christie, P. Cadmium distribution in rice plants grown in three different soils after application of pig manure with added cadmium. Environ. Geochem. Hlth. 2012, 34, 481-492. [CrossRef] [PubMed]

49. Gomez, D.; Nakazawa, T.; Furuta, N.; Smichowski, P. Multielemental chemical characterisation of fine urban aerosols collected in Buenos Aires and Tokyo by plasma-based techniques. Microchem. J. 2017, 133, 346-351. [CrossRef]

50. Fang, Y.; Sun, X.Y.; Yang, W.J.; Ma, N.; Xin, Z.H.; Fu, J.; Liu, X.C.; Liu, M.; Mariga, A.M.; Zhu, X.F.; et al. Concentrations and health risks of lead, cadmium, arsenic, and mercury in rice and edible mushrooms in China. Food Chem. 2014, 151, 379. [CrossRef]

51. Razzaque, M.S. Magnesium: Are we consuming enough? Nutrients 2018, 10, 1863. [CrossRef] [PubMed]

52. DiNicolantonio, J.J.; O'Keefe, J.H.; Wilson, W. Subclinical magnesium deficiency: A principal driver of cardiovascular disease and a public health crisis. Open Heart 2018, 5, e000668. [CrossRef]

53. Jiang, S.L.; Wu, J.G.; Feng, Y.; Yang, X.E.; Shi, C.H. Correlation analysis of mineral element contents and quality traits in milled rice (Oryza stavia L.). J. Agric. Food Chem. 2007, 55, 9608-9613. [CrossRef] [PubMed]

54. Shengzhe, E.; Jichao, Y.; Zhiyong, D.; Fengjuan, Y.; Xiaoping, Y.; Fuxiang, L. Effect of N, P, K, fertilizer on Fe, Zn, Cu, Mn, Ca, and Mg contents and yields in rice. Chin. J. Rice Sci. 2005, 19, 434-440, (In Chinese with English abstract).

55. Antoine, J.M.R.; Fung, L.A.H.; Grant, C.N.; Dennis, H.T.; Lalor, G.C. Dietary intake of minerals and trace elements in rice on the Jamaican market. J. Food Compos. Anal. 2012, 26, 111-121. [CrossRef]

56. Glahn, R.P.; Cheng, Z.; Welch, R.M.; Gregorio, G.B. Comparison of iron bioavailability from 15 rice genotypes: Studies using an in vitro digestion/Caco-2 cell culture model. J. Agric. Food Chem. 2002, 50, 3586-3591. [CrossRef]

57. Swamy, B.P.M.; Rahman, M.A.; Inabangan-Asilo, M.A.; Amparado, A.; Manito, C.; Chadha-Mohanty, P.; Reinke, R.; Slamet-Loedin, I.H. Advances in breeding for high grain Zinc in Rice. Rice 2016, 9, 49. [CrossRef]

58. Xiao, G.; Hu, Y.; Li, N.; Yang, D. Spatial autocorrelation analysis of monitoring data of heavy metals in rice in China. Food Control 2018, 89, 32-37. [CrossRef]

59. Tang, Y.; Liu, M.; Liu, X.; Wu, L.; Zhao, B.; Wu, C. Spatio-temporal index based on time series of leaf area index for identifying heavy metal stress in rice under complex stressors. Int. J. Environ. Res. Public Health 2020, 17, 2265. [CrossRef]

60. Chen, J.-H. The combined use of chemical and organic fertilizers and/or biofertilizer for crop growth and soil fertility. In Proceedings of the International Workshop on Sustained Management of the Soil-Rhizosphere System for Efficient Crop Production and Fertilizer Use, Land Development Department, Bangkok, Thailand, 16-20 October 2006; pp. 1-11.

61. Wang, F.; Lin, C.; Li, Q.H.; He, C.M.; Li, Y.; Lin, X.J. Effects of long-term fertilization on rice grain qualities and soil fertility factors in yellow paddy fields of southern China. Plant Nutr. Fertil. Sci. 2011, 17, 283-290.

62. Xiang, C.; Zhang, P.; Pan, G.; Qiu, D.; Chu, Q. Changes in diversity, protein content, and amino acid composition of earthworms from a paddy soil under different long-term fertilizations in the Tai Lake Region, China. Acta Ecologica Sinica 2006, 26, 1667-1673. [CrossRef] 
63. Park, J.-H.; Nam, S.-H.; Kim, Y.-O.; Kwon, O.-D.; An, K.-N. Comparison of quality, physiochemical and functional property between organic and conventional rice. J. Korean Soc. Food Sci. Nutr. 2010, 39, 725-730. [CrossRef]

64. Chung, I.M.; Kim, J.K.; An, Y.J.; Kwon, C.; Kim, S.Y.; Yang, Y.J.; Yarnes, C.T.; Chi, H.Y.; Kim, S.H. Compound-specific $\delta(13) C$ and $\delta(15) \mathrm{N}$ analyses of fatty acids and amino acids for discrimination of organic, pesticide-free, and conventional rice (Oryza sativa L.). Food Chem. 2019, 283, 305-314. [CrossRef]

65. Lu, C.Y.; Chen, H.H.; Teng, Z.Z.; Yuan, L.; Ma, J.; He, H.B.; Chen, X.; Zhang, X.D.; Shi, Y. Effects of N fertilization and maize straw on the dynamics of soil organic $\mathrm{N}$ and amino acid $\mathrm{N}$ derived from fertilizer N as indicated by N-15 labeling. Geoderma 2018, 321, 118-126. [CrossRef]

66. Rashid, M.M.; Jahan, M.; Islam, K.S. Impact of nitrogen, phosphorus and potassium on brown planthopper and tolerance of its host rice plants. Rice Sci. 2016, 23, 119-131. [CrossRef]

67. Kitta, K.; Ebihara, M.; Iizuka, T.; Yoshikawa, R.; Isshiki, K.; Kawamoto, S. Variations in lipid content and fatty acid composition of major non-glutinous rice cultivars in Japan. J. Food Compos. Anal. 2005, 18, 269-278. [CrossRef]

68. Zhang, Q.C.; Shamsi, I.H.; Xu, D.T.; Wang, G.H.; Lin, X.Y.; Jilani, G.; Hussain, N.; Chaudhry, A.N. Chemical fertilizer and organic manure inputs in soil exhibit a vice versa pattern of microbial community structure. Appl. Soil Ecol. 2012, 57, 1-8. [CrossRef]

69. Calder, P.C. Functional roles of fatty acids and their effects on human health. Jpen-Parenter Enter. 2015, 39, 18s-32s. [CrossRef] [PubMed] 